\title{
An IOT based Dynamic Garbage Level Monitoring System using Raspberry-pi
}

\author{
Harshita A. Gawad*, SurajKadam, Dona Jain, Nirav Patel \\ St. John College of Engineering and Manangement, Palghar. \\ *Email id: harshitagawad2707@gmail.com \\ Corresponding Author: Harshita A. Gawad
}

\begin{abstract}
In the present day scenario, many times we see that the Garbage bins or Dust bins placed at public places in the cities are overflowing due to increase in the waste every day. It creates unhygienic condition for the people and bad odour around the surroundings this leads in spreading some deadly diseases and human illness; to avoid such a situation we are planning to design Garbage Monitoring System using IoT. In this proposed system there are multiple dustbins located throughout the city or Campus, these dustbins are provided with low cost device which helps in tracking the level of garbage bins and an unique ID will be provided for every dustbin so that it is easy to identify which garbage bin is full. When the level reaches threshold limit, the device will transmit the level along with the unique ID provided. These details can be accessed by the concern authorities from their place with the help of Internet and an immediate action can be made to clean the dustbins.
\end{abstract}

Keywords:IoT, Arduino, RF Transceivers, Raspberry Pi, Ultrasonic Sensors

\section{INTRODUCTION}

Overflowing garbage bins have been cause of concern for residents in developing countries. With increase in population, the scenario of cleanliness with respect to garbage management is degrading tremendously. In our daily life, we see the pictures of garbage bins being overfull and all the garbage spills out resulting in pollution. Hence our problem statement is to design a system for collecting the garbage from a particular area whose public garbage bins are overflowing with prior concern. This project is proposed to keep the cities clean. This system monitors the garbage bins and informs about the level of garbage bins. This system uses ultrasonic sensors placed over the bins to detect the garbage level and compare it with the garbage bins depth.

A big Challenge in the urban cities is Solid waste management, not only in India but for most of the countries in the world [1]. This project gives us one of the most efficient ways to keep our environment clean and green.IoT and Raspberry Pi are the latest trends and are one of the best combinations to be used in the project. Hence, a combination of both these technologies is used in the project.

To give a brief description of this project, the sensors are placed in the common garbage bins at the public places. When the garbage reaches level of the sensor, then that indication will be given to Raspberry Pi. Then the details of it will be sent to the following web page via server.

\section{RELATED WORK}

Vikrant Bhor describes a system in which dustbins are interfaced with microcontroller based system with IR Sensors and RF modules. Where the IR sensor detects the level of dust in dustbin and sends the signals to microcontroller the same signal are encoded and sent through RF Transmitter and it is received and decoded by RF receiver at the Central System (Raspberry $\mathrm{Pi}$ ) and an Internet connection is enabled through a LAN cable from the modem. Once data has been received, it is analyzed and processed in the cloud, which displays the status of garbage in the dustbin on GUI on the web browser [2].

KanchanMahajan describes a system in which ZigBee, GSM and ARM 7 is used to form the integrated system to monitor the waste bins remotely. The sensors are placed in the common garbage bins at the public places. When the garbage reaches the level of sensor, then that indication will be given to ARM 7 Controller. The controller will give indication to the driver of garbage collection truck as to which garbage bin is completely filled and needs urgent attention. ARM 7 will give indication by sending SMS using GSM technology [3]. 
Vishesh Kumar describes a system in which a Infrared sensor is used to detect the garbage level in the dustbin. When sensor signal reaches to the threshold value, a mail notification will be sent to the respective Municipal/Government authority person. It is possible to observe the density of Dustbin through Internet on a Dashboard, this is a GUI so any of the authenticate person will easily check the present condition of the dustbin. So then that person can send the collection vehicle to collect the full garbage bins or dustbins [4].

\section{INTERNET OF THINGS}

IoT refers to the integration of objects, such as sensors, RFID tags or any device involving a communicating interface and a computing capability into the Internet. Internet of Things can be considered as a global network which allows the communication between human-to-human, humanto-things and things-to-things, which is anything in the world by providing unique identity to each and every object. Due to integration of the Internet of Things and World Wide Web started, with created the term Web of Things (WoT).

Characteristics of modern Web of Things:

- HTTP is used as main protocol for communication between devices.

- Device interfaces are made open.

- Smart devices expose their functionality through a REST interface thus any device is represented as a service.
IoT Application Platform: An IoT application platform is a solution that lives in the cloud, meaning it exists virtually somewhere on the Internet. This varies drastically from traditional solutions that are often deployed within the four walls of an institution. Contrary to those solutions, IoT application platforms thrive on being managed, maintained and accessible from virtually anywhere.

Cloud based, connected and driven by data, IoT application platforms provide users a means to implement business use cases otherwise difficult to achieve, such as predictive maintenance, pay-per-use and analytics. Real-time data translates to better business asset utilization and increased productivity [5] [6].

Table 1: Comparison between Traditional Internet AndIot

\begin{tabular}{|c|c|c|}
\hline Parameters & Traditional Internet & IoT \\
\hline Who creates the content? & Human & Machine \\
\hline How is content consumed? & By Request & $\begin{array}{l}\text { By pushing information and triggering } \\
\text { actions }\end{array}$ \\
\hline How is the content combined? & Using explicitly defined links & Through explicitly defined operators \\
\hline What is the value? & Answer questions & Action and timely information \\
\hline
\end{tabular}

\section{HARDWARE AND SOFTWARE} REQUIREMENTS

\section{A. Embedded Devices}

1. Raspberry Pi:

Raspberry $\mathrm{Pi}$ is small, powerful, cheap computer board. It is possible to work as a low-cost server to handle light internal or web traffic. Python language; it is main core language in Raspbian operating system.

The processor of Raspberry $\mathrm{Pi}$ is 32 bit, $700 \mathrm{MHz}$ system on a chip which is built on ARM 11 architecture. It has support for USB 2.0 which allows its expansion with large number of peripherals. Expansion and Communication with network devices over a LAN adapter are possible. It can run in server mode [7] [8].

2. Arduino:

The Arduino is a well-known open-source electronics prototyping platform, which is a central control unit of many embedded control applications ranging from interactive robotics to $3 \mathrm{D}$ printers. The Arduino receives commands from the master via USB connection, performs the requested operations and responds to the master. The response may contain just a confirmation or the requested data [9].

3. BeagleBone Black:

BeagleBone Black is a low-cost, communitysupported development platform for developers and hobbyists. Boot Linux in under 10 seconds and get started on development in less than 5 minutes with just a single USB cable [10].

4. Udoo:

Udoo is a family of open source single board computers and accessories merging the world of Arduino and physical computing with the Android/Linux programming. Udoo boards are therefore designed to be exploited both as a Mini PC for consumer use and as embedded system for makers and DIY enthusiasts as well as hardware startups and enterprises aiming to do fast prototyping without the initial production costs [11]. 
Table 2: Comparison Between Various Embedded Devices

\begin{tabular}{|c|c|c|c|c|}
\hline Specifications & Raspberry Pi & Arduino & BeagleBone Black & Udoo \\
\hline $\mathrm{CPU}$ & ARM BCM2835 & $\begin{array}{l}\text { ATMEGA8, } \\
\text { ATMEGA168, } \\
\text { ATMEGA328, } \\
\text { ATMEGA1280 }\end{array}$ & ARM Cortex-A8 & $\begin{array}{l}\text { MX6Quad, } \\
\text { 4xARM Cortex, } \\
\text { A9 core Atmel } \\
\text { SAM3X8E, } \\
\text { ARM Cortex- } \\
\text { M3 CPU }\end{array}$ \\
\hline RAM & $256-512 \mathrm{MB}$ & $16-32 \mathrm{kB}$ & $512 \mathrm{MB}$ & $1 \mathrm{~GB}$ \\
\hline LAN(Mbit) & $10 / 100$ & â"- & $10 / 100$ & $10 / 100 / 1000^{*}$ \\
\hline Analog Input & 0 & 6 & 6 & 14 \\
\hline OS support & $\begin{array}{l}\text { Raspbian, Ubuntu, Android, } \\
\text { ArchLinux, FreeBSD, } \\
\text { Fedora, RISC OS }\end{array}$ & Linux, Windows & Linux Angstrom & $\begin{array}{l}\text { Ubuntu, } \\
\text { Andriod, Linux }\end{array}$ \\
\hline Power & $5 \mathrm{~V} / \mathrm{USB}$ & $5 \mathrm{~V}$ & $5 \mathrm{~V}$ & $6-15 \mathrm{~V}$ \\
\hline $\begin{array}{c}\text { Programming } \\
\text { Language }\end{array}$ & C, C++, Java, Python & Arduino & Arduino & $\begin{array}{l}\text { Arduino, } \mathrm{C}, \\
\mathrm{C}++, \text { Java }\end{array}$ \\
\hline
\end{tabular}

\section{B. Sensing Devices}

\section{Optical Sensors:}

A fiber optic sensor is a sensor that uses optical fiber either as the sensing element, or as a means of relaying signals from a remote sensor to the electronics that process the signals. Fibers have many uses in remote sensing [12].

Fiber optic sensors are immune to electromagnetic interference, and do not conduct electricity so they can be used in places where there is high voltage electricity or flammable material such as jet fuel. Fiber optic sensors can be designed to withstand high temperatures.

2. Ultrasonic sensors:

Ultrasonic sensors emit a sound pulse that reflects off of objects entering the wave field. The reflected sound, or echo is then received by the sensor.

Detection of the sound generates an output signal for use by an actuator, controller, or computer.
The output signal can be analog or digital. Ultrasonic sensors are capable of detecting most objects metal or nonmetal, clear or opaque, liquid, solid, or granular that has sufficient acoustic reflectivity [13].

Another advantage of ultrasonic sensors is that they are less affected by condensing moisture than photoelectric sensors.

3. IR sensors:

An IR sensor is an electronic device that emits in order to sense some aspects of the surroundings. An IR sensor can measure the heat of an object as well as detects the motion. Usually in the infrared spectrum, all the objects radiate some form of thermal radiations. These types of radiations are invisible to our eyes that can be detected by an infrared sensor [14]. The emitter is simply an IR LED and the detector is simply an IR photodiode which is sensitive to IR light of the same wavelength as that emitted by the IR LED.

Table 3: Comparison of Ultra-Sonic Sensors with Other Devices

\begin{tabular}{|c|l|l|l|}
\hline Parameter & Optical Sensor & Ultrasonic Sensor & IR Sensor \\
\hline Detectable target & $\begin{array}{l}\text { Detection is affected by } \\
\text { target materials/colors }\end{array}$ & $\begin{array}{l}\text { Detection is unaffected by } \\
\text { target materials/colors }\end{array}$ & $\begin{array}{l}\text { Good for detecting the } \\
\text { proximity of an obstacle, } \\
\text { and not the range }\end{array}$ \\
\hline Detecting distance & $1000 \mathrm{~mm}$ & $10 \mathrm{~m}$ & $15-150 \mathrm{~cm}$ \\
\hline Effect of Dust/water & Affected & Unaffected & Unaffected \\
\hline
\end{tabular}

\section{Wireless Communication Devices \\ 1. WiFi:}

High data rate $(54 \mathrm{Mbit} / \mathrm{s}+)$ but also high power consumption. It is used when you need to connect directly to the Internet, such as an Internet-ofThings device, and have an external power source. 2. XBee:
XBee has low data rate $(250 \mathrm{kbit} / \mathrm{s})$ and low power consumption. It is used to make mesh-type sensor networks, each XBee device can communicate with each other and through each other via the mesh to devices that are out of range [5]. They are used for network of devices, particular home automation and sensors. 
3. RF:

nRF24L01 / RFM12B / RFM22B (SI4432) are popular proprietary transceivers. They can connect via SPI and have a lot of fancy features like low power modes, multiple channels, channel hopping, frequency calibration, CRC, retransmit and so on. The nRF24L01 operates in the $2.4 \mathrm{GHz}$ band. These are todays state of the art highly integrated and low cost hardware for reliable telemetry and consumer applications [16]. The range is between $10 \mathrm{~m}$ and $150 \mathrm{~m}$. The SI4432/RFM22B has the range of about $1.5 \mathrm{Km}$.

\section{Programming Languages}

1. JAVA:

JAVA is a programming language that developers use to create applications on your computer. Java also has a web plug-in that allows you to run apps in your browser [17].

2. $\mathrm{C}++$ :

$\mathrm{C}++$ is an object oriented programming (OOP) language, developed by BjarneStroustrup, and is an extension of $\mathrm{C}$ language. It is therefore possible to code $\mathrm{C}++$ in a "C style" or "object-oriented style" [18].

3. Python:

Python is a widely used high level, general purpose, and interpreted, dynamic programming language. Its design philosophy emphasizes code readability, and its syntax allows programmers to express concepts in fewer lines of code than possible in languages such as $\mathrm{C}++$ or Java. The language provides constructs intended to enable clear programs on both a small and large scale [19].

Table 4: Comparison Of Python With Different Languages

\begin{tabular}{|c|l|l|l|}
\hline & Python & JAVA & C++ \\
\hline 1. & Slower than JAVA & Faster than Python & Same as JAVA \\
\hline 2. & $\begin{array}{l}\text { It takes less time to } \\
\text { develop compared to } \\
\text { JAVA and C++ }\end{array}$ & $\begin{array}{l}\text { It takes more time to } \\
\text { complete compared to } \\
\text { python }\end{array}$ & $\begin{array}{l}\text { It takes a lot of time } \\
\text { to develop }\end{array}$ \\
\hline 3. & $\begin{array}{l}\text { Debugging methods are } \\
\text { easy }\end{array}$ & $\begin{array}{l}\text { Debugging methods are } \\
\text { easy }\end{array}$ & Same as JAVA \\
\hline
\end{tabular}

\section{Block Diagram}

Figure 1: Block Diagram of system

The module is divided into two parts Transmitter section and Receiver section. Here in the transmitter section we are using AVR microcontroller, RF transmitter and sensors these are attached to the dustbin. Sensors are used to detect the garbage level in the dustbin, whether the dustbin is full or empty. The sensor senses the content of the dustbin and sends the signals or the data to the microcontroller. The microcontroller reads the data from the sensor and process the data received from sensor, and the same data wirelessly transmitted to the Central system (Raspberry Pi) using RF Transmitter.

RF Transmitter is to transmit the signal from microcontroller to the Raspberry $\mathrm{Pi}$. The other section is receiver section in which RF Receiver, Raspberry $\mathrm{Pi}$ and Web Browser is used. RF Receiver is used to receive the data sent by $\mathrm{RF}$ transmitter. Raspberry Pi receives the data sent by the multiple transmitters and processes the data and the same data displayed to the use via Web Server.

\section{CONCLUSION}

The above work reviews various technologies that can be used to implement remote monitoring systems. Based on the comparison of various systems, techniques and algorithms we propose aIoT based Garbage Monitoring system. The system can be implemented using remote monitoring end devices are made from Arduino chipset. These nodes communicate with a central system that can be implemented on a standalone computer system. This system for the proposed system is implemented using a Raspberry Pi model. Communication between different devices can be achieved using RF based wireless communication modules. Finally the system status can be viewed via web browser which is in line with the IoT philosophy. Limitations of the system are in terms of dependence on reliability of communication modules. Since the sensor nodes are proposed to be deployed within the garbage cans, a physical damage can affect the communication or processing capability.

\section{REFERENCES}

[1]. Guerrero, LillianaAbarca, Ger Maas, and William Hogland, "Solid waste management challenges for cities in developing countries.", Waste management, 33.1 (2013): 220-232.

[2]. Vikrant Bhor, "Smart Garbage management System", International Journal of Engineering Research and Technology (IJERT), 2009, pp.103-110.

[3]. KanchanMahajan, "Waste Bin Monitoring System Using Integrated Technologies", International Journal of Innovative Research in Science, Issue 7, July 2014. 
[4]. Vishesh Kumar Kurre, "Smart Garbage Collection Bin overflow Indicator using IoT", International Research Journal of Engineering and Technology (IRJET), vol. 5, pp. 2288-2290, 2016.

[5]. Stankovic John A., "Research directions for the internet of things." IEEE Internet of Things Journal, 1.1 (2014): 3-9.

[6]. Gubbi, Jayavardhana, et al. "Internet of Things (IoT): A vision, architectural elements, and future directions.",Future Generation Computer Systems, 29.7 (2013): 1645-1660.

[7]. Maksimovi, Mirjana, et al. "Raspberry Pi as Internet of things hardware: performances and constraints.”,Design issues, 3 (2014): 8.

[8]. Kortas, Nawel, et al. "Communication within Cloudlet using the Raspberry.",Procedia Computer Science, 73 (2015): 193-198.

[9]. Teikari, Petteri, et al. "An inexpensive Arduino-based LED stimulator system for vision research.",Journal of neuroscience methods, 211.2 (2012): 227-236.

[10]. Coley, Gerald. "Beaglebone black system reference manual.",Texas Instruments, Dallas (2013).

[11]. Palazzetti, Emanuele, "Getting Started with UDOO.",Packt Publishing Ltd, 2015.

[12]. Dickinson, Todd A., et al. "A chemicaldetecting system based on a cross-reactive optical sensor array.",Nature, 382.6593 (1996): 697-700.

[13]. Gutierrez, Jose M., et al., "Smart Waste Collection System Based on Location Intelligence.",Procedia Computer Science, 61 (2015): 120-127.

[14]. Mohammad, Tarek., "Using ultrasonic and infrared sensors for distance measurement.", World Academy of Science, Engineering and Technology, 51 (2009): 293-299.

[15]. Yawut, Cholatip, and SathapathKilaso., "A wireless sensor network for weather and disaster alarm systems.",Proc. International Conference on Information and Electronics Engineering, IPCSIT., Vol. 6. 2011.
[16]. Hong, Gao, and Su Jianxiu, "Design of the temperature signal wireless receiver and display system on polishing interface in chemical mechanical polishing.", Procedia Engineering, 24 (2011): 417-421.

[17]. Savitch, Walter, and Frank M. Carrano, "Java: Introduction to Problem Solving and Programming”, Prentice Hall Press, 2008.

[18]. Ortega, James M., and Andrew S. Grimshaw, "An Introduction to $\mathrm{C}++$ and numerical methods.", Oxford University Press, 1998.

[19]. Guzdial, Mark J., and Barbara Ericson., “ Introduction to computing and programming in Python, a multimedia approach.", Prentice Hall Press, 2009.

International Journal of Engineering Research and Applications (IJERA) is UGC approved Journal with S1. No. 4525, Journal no. 47088. Indexed in Cross Ref, Index Copernicus (ICV 80.82), NASA, Ads, Researcher Id Thomson Reuters, DOAJ.

International Journal of Engineering Research and Applications (IJERA) is UGC approved Journal with
S1. No. 4525, Journal no. 47088. Indexed in Cross Ref, Index Copernicus (ICV 80.82), NASA, Ads,
Researcher Id Thomson Reuters, DOAJ.
Harshita A. Gawad. "An IOT based Dynamic Garbage Level Monitoring System using
Raspberry-pi." International Journal of Engineering Research and Applications (IJERA) 7.7
(2017): 30-34. 